\title{
Lord of The Crowns: A New Precious In The Kingdom of Clustomesogens
}

\author{
Kevin Guy, ${ }^{[a]}$ Philipp Ehni, ${ }^{[b]}$ Serge Paofai, ${ }^{[a]}$ Claire Roiland, ${ }^{[a]}$ Maria Amela-Cortes ${ }_{[b]}{ }^{[a]}$ \\ Stéphane Cordier, ${ }^{[a]}$ Sabine Laschat, ${ }^{*[b]}$ and Yann Molard ${ }^{*[a]}$ Robert Forschner
}

\begin{abstract}
Replacing pure inorganic materials by functional organicinorganic hybrid ones to lower production costs has become a major challenge, in particular for the optoelectronic industry. Adding nanostructuration abilities meanwhile preserving homogeneity is even more challenging for this class of new materials. Here we show that Red-NIR emissive ternary molybdenum cluster salts can be assembled to liquid crystalline $15 \mathrm{C} 5$ crown ethers. The resulting hybrids are homogeneous and stable up to high temperature despite the weakness of the supramolecular interactions binding both components. These are illustrated by ${ }^{133} \mathrm{Cs}$ MAS NMR. All hybrids show hexagonal columnar arrangements and strong Red-NIR emission. Surprisingly, when chlorinated clusters are used instead of brominated ones, the mesophase stability is largely enhanced.
\end{abstract}

Organic materials containing inorganic luminophores have become in recent years very attractive for optoelectronic, lighting or photovoltaic applications. While the organic matrix offers its excellent processability, the inorganic counterpart can provide a stable and intense emission. Thus, active layers can be deposited on a targeted substrate using large-scale and low-cost production means like dip- or spin-coating, drop casting or printing. ${ }^{[1]}$

Besides a careful design of the material dedicated to prevent selfaggregation processes, controlling its nanostructuration is particularly challenging. It implies using materials, fluid enough for being able to self-arrange, endowed of self-correction abilities, and, able to react easily to a low cost external stimulus such as e.g. a temperature change or an electric current. Liquid crystals (LC) fulfill all these requirements and represent matrices of choice to self-organize new functionalities into a single material. ${ }^{[2]}$

So far, the homogeneous integration of functional inorganic nanocomponents like nanoparticles or nanorods in liquid crystals relies on their functionalization with organic liquid crystalline promoters or compatibilizers either by covalent grafting ${ }^{[3]}$ or electrostatic interactions. ${ }^{[4]}$ Yet, employing soft supramolecular interactions like host-guest interactions has been scarcely explored in this context. ${ }^{[5]}$ This could eventually be explained by their weakness which, could destabilize the organic-inorganic assemblies, especially for thermotropic LC materials. Few

[a] K. Guy, S. Paofai, Dr. C. Roiland, Dr. M. Amela-Cortes, Dr. S. Cordier, Dr. Y. Molard Univ Rennes, CNRS, ISCR - UMR 6226, ScanMAT - UMS 2001, F35000 Rennes, France

E-mail : yann.molard@univ-rennes1.fr

[b] P. Ehni, Pr. S. Laschat

Institute of Organic Chemistry, University of Stuttgart, Pfaffendwaldring 55, 70569, Stuttgart, Germany; Sabine.Laschat@oc.uni-stuttgart.de

Supporting information for this article is given via a link at the end of the document. examples are described in the literature where monometallic complexes are made of emissive metallic cations with liquid crystalline $18 \mathrm{C} 6$ crown ethers, or azacrowns ${ }^{[6]}$ Hence columnar materials containing $\mathrm{Eu}^{3+}$ or $\mathrm{Tb}^{3+}$ were studied. ${ }^{[7]}$ Fluorescence intensity in discotic dibenzocoronene tetracarboxydiimide increased selectively upon addition of $\mathrm{Pb}^{2+} \cdot{ }^{[8]}$ Recently, we used a 18C6 crown ether backbone and functionalized it to develop nematic $^{[9]}$ or discotic clustomesogens ${ }^{[10]}$ i.e. metallic cluster containing liquid crystals.

Metal clusters are assemblies of metal atoms maintained by metal - metal bonds (Figure 1). ${ }^{[11]}$ With their nanometric size and discret energy levels, they represent intermediates between coordination complexes and nanoparticles. Within this compound family, obtained by high temperature solid state chemistry routes, octahedral metal cluster compounds of general formula $A_{2} M_{6} L^{i}{ }_{8} L_{6}{ }_{6}\left(A=\right.$ alkali cation, $M=M o, R e$, or $W, L^{i}=$ inner or facecapping ligand, halogen or chalcogen; $\mathrm{L}^{\mathrm{a}}=$ apical ligand, halogen or organic fragment, Figure 1) are relevant compounds for optoelectronic applications. ${ }^{[12]}$ Depending on the environment and nature of the octahedral metallic scaffold, they show a stable phosphorescence in the red-NIR with high quantum yield values that depend on their substituents $\left(L^{\mathrm{i}}\right.$ and $\left.L^{\mathrm{a}}\right),{ }^{[13]}$ a large Stoke shift and lifetimes in the microseconds range. ${ }^{[14]}$ Once their ceramiclike behavior can be overcome, they represent realistic alternatives to rare earth luminophores needing organic antenna to become efficient emitters, lead containing hybrid perovskites which, beside their poor photostability, possess small Stoke shifts and suffer from reabsorption, ${ }^{[15]}$ cadmium containing quantum dots that undergo photoblinking ${ }^{[16]}$ or finally organic dyes showing photobleaching. ${ }^{[17]}$ Here, we show that ceramic-like transition metal cluster compounds can be introduced in thermotropic LC, using extremely weak supramolecular interactions between 15C5 crown ether derivatives (Figure 1) and either $\mathrm{Cs}^{+}$or $\mathrm{K}^{+}$cations acting as the anionic cluster counter-ion. It is known that $15 \mathrm{C} 5$ crown ether can form weak sandwich complexes with $\mathrm{Cs}^{+}(2: 1$ stoichiometry) or $1: 1$ complexes with $\mathrm{K}^{+}$cations. ${ }^{[18]}$ However, to the best of our knowledge, no examples have been reported so far where these weak and reversible interactions are used to design functional materials. We present herein the first hybrid material based on weak interactions between several LC 15 C5 crown-ethers and emissive inorganic metal cluster salts. Using the described soft strategy allows keeping the intrinsic properties of emitters unchanged while it improves the LC temperature range of ligands.

Three cluster salts namely $\mathrm{Cs}_{2} \mathrm{Mo}_{6} \mathrm{Br}_{14}, \mathrm{Cs}_{2} \mathrm{Mo}_{6} \mathrm{Cl}_{14}$ and $\mathrm{K}_{2} \mathrm{Mo}_{6} \mathrm{Cl}_{14}$ were used in these studies. They were obtained by high temperature solid state synthesis as crystalline powder following reported procedures and were chosen for their good thermal stability that is mandatory to develop thermotropic hybrids. ${ }^{[19]}$ As depicted in Figure 1, three ligands were used to design hybrids. Differences between these ligands rely on the 
nature of atoms linking the o-terphenylphenyl moieties to the dodecyl side chains. Indeed, some of us showed recently that using sulfur atoms instead of oxygen atoms modify significantly the ligand's liquid crystalline phase stability. ${ }^{[20]}$ Replacing oxygen by the bulkier sulfur led to decreased LC-to-isotropic state transition temperatures (clearing temperatures) and increased mesophase range, presumably due to a less tight intracolumnar packing but improved nanoseggregation. We could then expect the same effect for our complexes. Hybrids were obtained by mixing under stoichiometric conditions a solution of ligand dissolved in dichloromethane with a solution of crystalline powder of metal cluster compound dissolved in acetonitrile. After stirring overnight at $50^{\circ} \mathrm{C}$ and evaporation, mixtures were solubilized in a minimum of dichloromethane, filtrated to remove any unreacted metal cluster compound with a microfilter, and evaporated to dryness under vacuum to give the corresponding complexes.

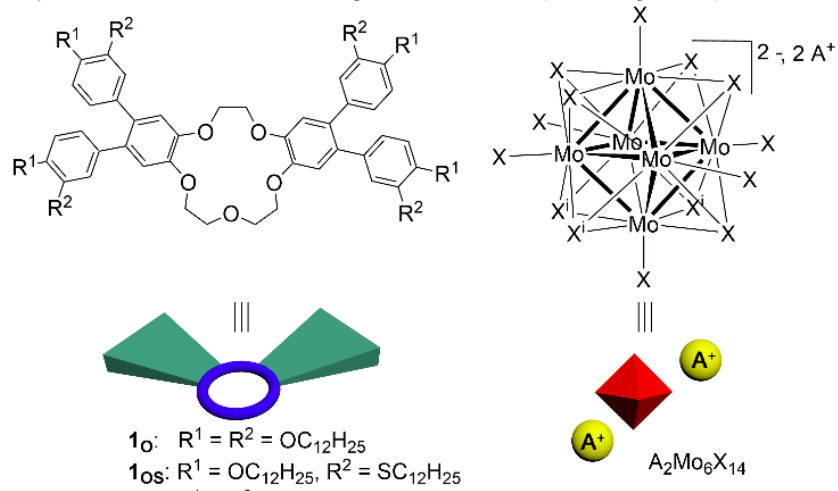

1os: $\mathrm{R}^{1}=\mathrm{OC}_{12} \mathrm{H}_{25}, \mathrm{R}^{2}=\mathrm{SC}_{12} \mathrm{H}_{25}$

1s: $\mathrm{R}^{1}=\mathrm{R}^{2}=\mathrm{SC}_{12} \mathrm{H}_{25}$

$4\left(\mathbf{1}_{\mathrm{o}}\right)+\mathrm{Cs}_{2}\left[\mathrm{Mo}_{6} \mathrm{Br}_{14}\right] \rightarrow\left[\left(\mathbf{1}_{\mathrm{o}}\right)_{2}: \mathrm{Cs}_{2}\left[\mathrm{Mo}_{6} \mathrm{Br}_{14}\right]=\mathbf{2}\right.$ 。 $4\left(1_{\text {os }}\right)+\mathrm{Cs}_{2}\left[\mathrm{Mo}_{6} \mathrm{Br}_{14}\right] \rightarrow\left[\left(\mathbf{1}_{\text {os }}\right)_{2}: \mathrm{Cs}_{2}\left[\mathrm{Mo}_{6} \mathrm{Br}_{14}\right]=\mathbf{2}_{\text {os }}\right.$ $4\left(1_{\mathrm{s}}\right)+\mathrm{Cs}_{2}\left[\mathrm{Mo}_{6} \mathrm{Br}_{14}\right] \rightarrow\left[\left(1_{\mathrm{s}}\right)_{2}: \mathrm{Cs}\right]_{2}\left[\mathrm{Mo}_{6} \mathrm{Br}_{14}\right]=2_{\mathrm{s}}$ $4\left(\mathbf{1}_{\mathrm{O}}\right)+\mathrm{Cs}_{2}\left[\mathrm{Mo}_{6} \mathrm{Cl}_{14}\right] \rightarrow\left[\left(\mathbf{1}_{\mathrm{o}}\right)_{2}: \mathrm{Cs}_{2}\left[\mathrm{Mo}_{6} \mathrm{Cl}_{14}\right]=3_{\mathrm{Cs}}\right.$ $2\left(1_{0}\right)+\mathrm{K}_{2}\left[\mathrm{Mo}_{5} \mathrm{Cl}_{14}\right] \rightarrow\left[\left(1_{0}\right): \mathrm{K}_{2}\left[\mathrm{Mo}_{6} \mathrm{Cl}_{14}\right]=3_{\mathrm{K}}\right.$
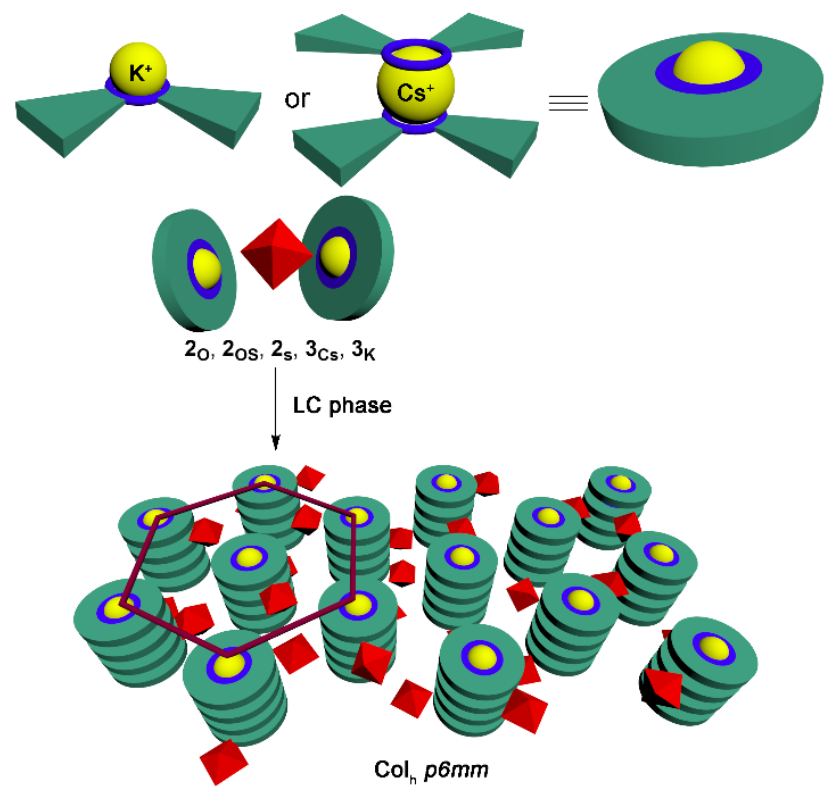

Figure 1. Representation of $15 \mathrm{C} 5$ crown ether derivatives, $\mathrm{A}_{2} \mathrm{Mo}_{6} \mathrm{X}_{14}$ transition metal cluster compound salts, synthesized complexes and hybrids selfarrangement in the liquid crystalline phase.
Solid state MAS ${ }^{133} \mathrm{Cs}$ experiments were realized with 20 and $\mathbf{2}$ os. Obtained spectra were compared to the one recorded for the crystalline powder of $\mathrm{Cs}_{2} \mathrm{Mo}_{6} \mathrm{Br}_{14}$ (ESI, Figure S1). While two signals corresponding to the two crystallographic positions within the single crystal X-ray structure are observed for $\mathrm{Cs}_{2} \mathrm{Mo}_{6} \mathrm{Br}_{14}$, spectra recorded for 20 and 2 os contain only one broad signal located at $-27 \mathrm{ppm}$, indicating i) the equivalence of $\mathrm{Cs}^{+}$cations within the hybrids, ii) that the interactions strength between the $15 \mathrm{C} 5$ crown and the cations are similar. The signal broadness is due to weak dipolar interactions between ${ }^{133} \mathrm{Cs}$ ions and protons located on the 15C5 ring. ${ }^{[21]}$ It also illustrates the weakness and reversibility of the equilibrium on the NMR timescale. Note that when $\mathrm{Cs}^{+}$cluster salts are integrated in organic polymers containing polyethylenoxide side chains, the observed NMR signals are sharper. ${ }^{[22]}$

LC properties were studied by polarized optical microscopy (POM, Figures S2-S4) differential scanning calorimetry (DSC, Figures S5-S7), and wide and small angle X-ray scattering (WAXS and SAXS, see ESI Figures S8-S13 for diffractograms). Thermodynamic data, mesophase identification and parameters are gathered in Table 1, together with the ligand precursors for comparison. ${ }^{[20,23]}$ All complexes show an enantiotropic hexagonal columnar mesophase whose temperature range is enhanced as compared to the pure ligand. This phenomenon was already observed when a larger 18C6 crown ether was used instead of $15 \mathrm{C} 5$ and is attributed to the cluster polyionicity that insure a better stability of the supramolecular assemblies upon heating. ${ }^{[10]}$ Unexpectedly, $\mathrm{Cs}_{2} \mathrm{Mo}_{6} \mathrm{Cl}_{14}$ complexation enhances significantly the mesophase stability compared to $\mathrm{Cs}_{2} \mathrm{Mo}_{6} \mathrm{Br}_{14}$. Indeed, the clearing temperature increases from $96^{\circ} \mathrm{C}$ to $137{ }^{\circ} \mathrm{C}$ when passing from the brominated to the chlorinated hybrid. Hence, the electrostatic interactions binding the anionic clusters to $\mathrm{Cs}^{+}$are different in both cases, and depend on the inner and apical ligand nature. As these ligands can be modified by combining solution and solid state chemistry routes, one can expect to modulate the liquid crystal stability of hybrids by modifying the cluster nature. Such behavior opens wide perspectives in terms of functional material design and is worth pursuing. Introducing, $\mathrm{K}^{+}$cluster counter-cations instead of $\mathrm{Cs}^{+}$cations, has also a pronounced effect on the mesophase stability. Indeed, the clearing temperature of $3 \mathrm{k}$ is $40^{\circ} \mathrm{C}$ higher than the one of $3 \mathrm{cs}$. Although electrostatic interactions strength is partly responsible for such modulation, the increase of the inorganic/organic ratio when $\mathrm{K}$ is used instead of Cs plays certainly a major role; two equivalents of ligand are necessary to obtain a homogeneous hybrid with $\mathrm{K}_{2} \mathrm{Mo}_{6} \mathrm{Cl}_{14}$ while four equivalents are mandatory with $\mathrm{Cs}_{2} \mathrm{Mo}_{6} \mathrm{Cl}_{14}$. For $2 \mathrm{~s}$ and 2 os complexes, the LC temperature range was determined by POM as DSC traces remained silent, either on heating or cooling the samples. Homogeneity and stability of hybrids were confirmed and illustrated by optical microscopy taken under UV irradiation in the LC state: A red emission spread homogeneously on all samples. Observed mesophases could be unambiguously identified for 20 and 20 s from POM while $2_{S}$ gave only a sandy texture. SAXS and WAXS diffractograms were then necessary to determine the columnar nature of $2 \mathrm{~s}$ in the mesophase. Yet, in all cases, despite the non-centrosymmetrical structure of ligands, hexagonal columnar arrangement were observed for all hybrids. Lattice parameters calculated for hybrids are slightly higher than for native crown ether which is in good 
accordance with the integration of metallic clusters within the structure. The intracolumnar spacing between crowns deduced from the halo observed in the wide angle section of the diffractograms increased slightly upon complexation of the 1o ligand, whereas the values did not change upon complexation of 1 s or 1 os.

Table 1. Thermodynamic and X-ray diffraction data for ligands and hybrid compounds

\begin{tabular}{|c|c|c|c|c|c|}
\hline & Transition & $\mathrm{T} /{ }^{\circ} \mathrm{C}$ & $\Delta \mathrm{Cp} / \Delta \mathrm{H}$ & Mesophase & $\begin{array}{l}\text { Lattice } \\
\text { spacing }[\AA]]\end{array}$ \\
\hline \multirow[t]{2}{*}{ 1s } & $\mathrm{Cr} \rightarrow \mathrm{Col}_{\mathrm{h}}$ & -12 & $-14.6^{a}$ & $\begin{array}{l}\mathrm{Col}_{\mathrm{h}} \text { at } 22^{\circ} \mathrm{C}- \\
\text { p6mm }\end{array}$ & $\begin{array}{l}\mathrm{a}=37.0 \\
\mathrm{~h}=4.4\end{array}$ \\
\hline & $\mathrm{Col}_{\mathrm{h}} \rightarrow \mathrm{I}$ & 27 & $-7^{a}$ & & \\
\hline \multirow[t]{2}{*}{$2 s$} & $\mathrm{Cr} \rightarrow \mathrm{Colh}$ & - & - & $\begin{array}{l}\text { Colh at } 40^{\circ} \mathrm{C}- \\
\text { p6mm }\end{array}$ & $\begin{array}{l}\mathrm{a}=39.60 \\
\mathrm{~h}=4.37\end{array}$ \\
\hline & $\mathrm{Col}_{\mathrm{h}} \rightarrow \mathrm{I}$ & $59^{b}$ & - & & \\
\hline \multirow[t]{2}{*}{ 1os } & & -11 & & $\begin{array}{l}\text { Colh at } 30^{\circ} \mathrm{C}- \\
\text { p6mm }\end{array}$ & $\begin{array}{l}\mathrm{a}=38.1 \\
\mathrm{~h}=4.3\end{array}$ \\
\hline & $\mathrm{Col}_{\mathrm{h}} \rightarrow \mathrm{I}$ & 52 & $-5.5^{a}$ & & \\
\hline \multirow[t]{2}{*}{$20 s$} & $\mathrm{~g} \rightarrow$ Colh & - & - & $\begin{array}{l}\text { Coln at } 70^{\circ} \mathrm{C} \\
\text { p6mm }\end{array}$ & $\begin{array}{l}a=39.28 \\
h=4.43\end{array}$ \\
\hline & $\mathrm{Col}_{\mathrm{h}} \rightarrow \mathrm{I}$ & $75^{b}$ & - & & \\
\hline \multirow[t]{2}{*}{10} & $\mathrm{Cr} \rightarrow \mathrm{Col}_{\mathrm{h}}$ & 46 & & $\begin{array}{l}\text { Colh at } 52^{\circ} \mathrm{C} \\
\text { p6mm }\end{array}$ & $\begin{array}{l}\mathrm{a}=39.3 \\
\mathrm{~h}=4.4\end{array}$ \\
\hline & Coln $\rightarrow 1$ & 78 & $-7.5^{\mathrm{a}}$ & & \\
\hline \multirow[t]{2}{*}{20} & $\mathrm{~g} \rightarrow \mathrm{Col}_{\mathrm{h}}$ & - & - & $\begin{array}{l}\text { Colh at } 100^{\circ} \mathrm{C} \\
P 6 m m\end{array}$ & $\begin{array}{l}a=40.07 \\
h=4.52\end{array}$ \\
\hline & $\mathrm{Col}_{\mathrm{h}} \rightarrow \mathrm{I}$ & 96.4 & $-11.5^{\mathrm{a}}$ & & \\
\hline \multirow[t]{2}{*}{$3 \mathrm{cs}$} & $\mathrm{Cr} \rightarrow \mathrm{Col}_{\mathrm{h}}$ & 107.5 & $-7.0^{\mathrm{a}}$ & $\begin{array}{l}\mathrm{Col}_{\mathrm{h}} \text { at } 135^{\circ} \mathrm{C} \\
\mathrm{P} 6 \mathrm{~mm}\end{array}$ & $\begin{array}{l}a=39.60 \\
h=4.75\end{array}$ \\
\hline & Coln $\rightarrow 1$ & 137.1 & $-9.1^{a}$ & & \\
\hline \multirow[t]{2}{*}{$3 k$} & $\mathrm{~g} \rightarrow$ Colh $_{\mathrm{h}}$ & $97.7^{\mathrm{b}}$ & - & $\begin{array}{l}\text { Coln at } 140^{\circ} \mathrm{C} \\
P 6 m m\end{array}$ & $\begin{array}{l}\mathrm{a}=39.55 \\
\mathrm{~h}=4.88\end{array}$ \\
\hline & $\mathrm{Col}_{\mathrm{h}} \rightarrow \mathrm{I}$ & 178.6 & $-6.0^{a}$ & & \\
\hline
\end{tabular}

[a] in $\mathrm{KJ} \mathrm{mol}^{-1}$ [b] temperature observed by P.O.M.; Cr: crystalline state, Colr: columnar rectangular; Coln: columnar hexagonal; I: isotropic state

Emission properties were studied in the glassy or crystalline state for hybrids and compared to the emission properties of their corresponding cluster precursor measured either in the solid state or in solution. All samples emit in the red-NIR area. Calculated absolute quantum yield (AQY) values and kinetic parameters are gathered in Table 2. At $25^{\circ} \mathrm{C}$, interactions between cluster compounds and macrocycles do not modify the shape and position of the emission maximum which shows that the nature of the cluster emissive triplet state is not affected by the complexation at a given temperature. However, temperature dependent emission studies realized on $\mathrm{Cs}_{2} \mathrm{Mo}_{6} \mathrm{Br}_{14}$ and the $2 \mathbf{x}(\mathrm{x}$ $=\mathrm{O}, \mathrm{S}, \mathrm{OS}$ ) compounds from $-100^{\circ} \mathrm{C}$ up to $200^{\circ} \mathrm{C}$ revealed that the cluster emissive state is significantly affected i) by a temperature change (Figure 2, Figures S14-S17) and ii) by the cation complexation within the crown. Although broad, the emission profile could be deconvoluted in several contributions whose weight depends on the temperature. At low temperature, the main contributions are centred on $770 \mathrm{~nm}$ and $856 \mathrm{~nm}$ while at high temperature the most important contribution is centered around $697 \mathrm{~nm}$ (see ESI, Figure S18 and Table S1). Thus, the emission is blue-shifted upon heating. ${ }^{[14 b]}$ It is known that cluster compound emission can arise from different triplet states, and it might explain why this shift is observed.[24] This known behavior $^{[14 b, 25]}$ is similar when the cluster salt is part of the LC material. However, the intensity vs temperature dependence varies significantly when cluster salts are interacting with the $15 \mathrm{C} 5$ crowns. ${ }^{[10]}$ Inset of Figure 2, that reports $\mathrm{I} / \mathrm{I}_{-100^{\circ} \mathrm{C}}$ for various temperatures and hybrids, clearly illustrates the effect of cluster compound complexation on its emission properties. In particular, the emission intensity decreases less in the range $\left[0-200^{\circ} \mathrm{C}\right]$ when the cluster salt interacts with the $15 \mathrm{C} 5$ crown. The $15 \mathrm{C} 5$ nature of substituents seems also to have an impact on this parameter as a loss of $61 \%, 36 \%$ and $25 \%$ of the initial intensity measured at $100^{\circ} \mathrm{C}$ is observed for $2 \mathrm{o}, 2 \mathrm{os}$, and $2 \mathrm{~s}$ respectively (the loss is about $86 \%$ for $\mathrm{Cs}_{2} \mathrm{Mo}_{6} \mathrm{Br}_{14}$ ). Hybrids $\mathrm{AQY}$ values are very similar to those of their cluster precursor taken in deaerated solution which shows that the cluster emission efficiency is maintained in the complexes. The atmosphere dependency of $A Q Y$ values are due to the nanocluster excited state quenching by triplet oxygen and is known to generate the emissive $\mathrm{O}_{2}\left({ }^{1} \Delta_{\mathrm{g}}\right) \cdot{ }^{[26]}$ Irradiating hybrids between 365 and $450 \mathrm{~nm}$ did not affect significantly their $A Q Y$, as expected, except for the $2 \mathrm{~s}$ derivative (ESI Figure S20). In this case, a maximum AQY value was calculated at a $400 \mathrm{~nm}$ excitation. The reason of this modulation, also observed when $A Q Y$ measurements were realized under $\mathrm{N}_{2}$ atmosphere, is not yet clearly identified.

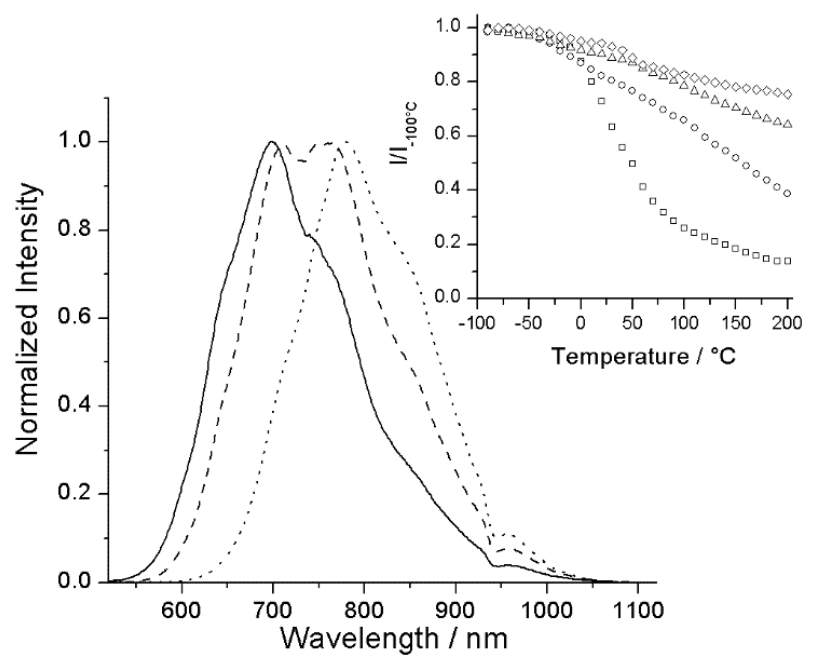

Figure 2. Normalized emission spectra of $\mathrm{Cs}_{2} \mathrm{Mo}_{6} \mathrm{Br}_{14}$ at $200^{\circ} \mathrm{C}$ (plain line), $0^{\circ} \mathrm{C}$ (dashed line) and $-100^{\circ} \mathrm{C}$ (dotted line); Inset: temperature vs $\mathrm{I} / \mathrm{I}_{-100^{\circ} \mathrm{C}}$ at $758 \mathrm{~nm}$ for $\mathrm{Cs}_{2} \mathrm{Mo}_{6} \mathrm{Br}_{14}$ (square), 2o (circle), 2os (triangle) and 2s (diamond).

Phosphorescence lifetime decays in the range of $113-175 \mu \mathrm{s}$ could be calculated for deaerated acetone solution containing the cluster precursors, values consistent with previously reported ones for $\mathrm{Mo}_{6}$ based compounds. ${ }^{[14 \mathrm{~b}]}$ (see ESI, Figures S21-S31 for emission decay profiles). Hybrids emission decay profiles measured in the glassy state were fitted with two components. This bi-exponential behaviour, also observed for powdered $\mathrm{Cs}_{2} \mathrm{Mo}_{6} \mathrm{Br}_{14}$, or when clusters were embedded in polymers or LC matrices, could arise from the cluster core dual emission 
abilities $^{[24]}$ but more likely to excitation-energy transfer from clusters to energy trap sites (e.g. surface defects). ${ }^{[27]}$

In conclusion, we have shown that, transition metal cluster salts can be associated to $15 \mathrm{C} 5$ containing mesomorphic organic compounds. Although very weak, interactions between the $15 \mathrm{C5}$ crowns and the cluster $\mathrm{Cs}^{+}$or $\mathrm{K}^{+}$cations are able to maintain the supramolecular assemblies even at high temperature. We also demonstrated that the cluster salts enhance the mesophase stability of the native organic ligand, meanwhile adding their intrinsic properties such as a strong luminescence in the red-NIR. Unexpectedly, the nature of the alkali cation contained within the ternary cluster salt is not the only one responsible for the mesophase stability enhancement. The nature of metal cluster face-capping inner and terminal apical ligands also affects the mesophase stability. This specific point opens wide perspectives for the development of functional hybrid materials with tailored liquid crystal properties. It will be investigated in more details in the near future.

Table 2. Absolute Quantum Yields calculated at $22^{\circ} \mathrm{C}\left(\lambda_{\text {exc }}=365 \mathrm{~nm}\right)$ and kinetic parameters obtained under $375 \mathrm{~nm}$ irradiation.

\begin{tabular}{cccc}
\hline & $\Phi_{\mathrm{em}}$ & \multicolumn{2}{c}{ Kinetic parameters } \\
\hline & Air $/ \mathrm{N}_{2}$ & $\tau_{1} / \mu \mathrm{s}(\%)$ & $\tau_{2} / \mu \mathrm{s}(\%)$ \\
\hline $2 \mathrm{~s}$ & $0.11 / 0.15$ & $27(0.49)$ & $68(0.51)$ \\
\hline 2 os & $0.07 / 0.17$ & $24(0.88)$ & $58(0.12)$ \\
\hline 20 & $0.08 / 0.16$ & $18(0.87)$ & $54(0.13)$ \\
\hline $3_{\mathrm{cs}}$ & $0.10 / 0.21$ & $12(0.88)$ & $54(0.12)$ \\
\hline $3_{\mathrm{K}}$ & $0.05 / 0.16$ & $21(0.75)$ & $55(0.25)$ \\
\hline $\mathrm{Cs}_{2} \mathrm{Mo}_{6} \mathrm{Br}_{14}{ }^{\mathrm{a}}$ & $0.15 /-$ & $33(0.50)$ & $89(0.50)$ \\
\hline $\mathrm{Cs}_{2} \mathrm{Mo}_{6} \mathrm{Br}_{14}{ }^{\mathrm{b}}$ & $0.03 / 0.15$ & $113^{\mathrm{c}}$ & - \\
\hline $\mathrm{Cs}_{2} \mathrm{Mo}_{6} \mathrm{Cl}_{14}{ }^{\mathrm{a}}$ & $0.11 /-$ & 169 & - \\
\hline $\mathrm{Cs}_{2} \mathrm{Mo}_{6} \mathrm{Cl}_{14}{ }^{\mathrm{b}}$ & $0.02 / 0.19$ & $175^{\mathrm{c}}$ & - \\
\hline $\mathrm{K}_{2} \mathrm{Mo}_{6} \mathrm{Cl}_{14}{ }^{\mathrm{a}}$ & $0.06 /-$ & 156 & - \\
\hline $\mathrm{K}_{2} \mathrm{Mo}_{6} \mathrm{Cl}_{14}{ }^{\mathrm{b}}$ & $0.01 / 0.19$ & $161^{\mathrm{c}}$ & - \\
\hline
\end{tabular}

a in powder; ${ }^{b}$ in acetone at $\mathrm{c}=10^{-5} \mathrm{~mol}^{\mathrm{I}} \mathrm{I}^{-1} ;{ }^{\mathrm{c}}$ value calculated in deaerated solution

\section{Acknowledgements}

This work was partly financed by the bilateral PHC Procope project "PLISE" $n^{\circ}$ 37689XA and ANR Clustomesogen ANR-13BS07-0003-01.

Keywords: cluster compound • Self-assembly • Organicinorganic hybrid composites $•$ liquid crystal $\bullet$ energy conversion

[1] a) W. U. Huynh, J. J. Dittmer, A. P. Alivisatos, Science 2002, 295, 2425 b) F. Meinardi, H. McDaniel, F. Carulli, A. Colombo, K. A. Velizhanin, N S. Makarov, R. Simonutti, V. I. Klimov, S. Brovelli, Nat. Nanotechnol. 2015, 10, 878; c) S. Masi, S. Colella, A. Listorti, V. Roiati, A. Liscio, V. Palermo, A. Rizzo, G. Gigli, Sci. Rep. 2015, 5, 7725; d) S. Parola, B Julián-López, L. D. Carlos, C. Sanchez, Adv. Funct. Mater. 2016, 26, 6506.

[2] T. Kato, J. Uchida, T. Ichikawa, T. Sakamoto, Angew. Chem. Int. Ed. 2018, 57, 4355

[3] H. Qi, T. Hegmann, J. Mater. Chem. 2006, 16, 4197.
[4] S. Umadevi, V. Ganesh, T. Hegmann, in Handbook of Liquid Crystals (2nd Edition) Volume 6: Nanostructured and Amphiphilic Liquid Crystals, Vol. 6 (Eds.: J. W. Goodby, P. J. Collings, T. Kato, C. Tschierske, H. F. Gleeson, P. Raynes), Wiley-VCH Verlag GmbH \& Co. KGaA, 2014, pp 27.

[5] Y. Molard, Acc. Chem. Res. 2016, 49, 1514

[6] a) G. X. He, F. Wada, K. Kikukawa, S. Shinkai, T. Matsuda, J. Org. Chem. 1990, 55, 548; b) G. X. He, F. Wada, K. Kikukawa, T. Matsuda, Chem. Commun. 1987, 1294; c) J. M. Lehn, J. Malthete, A. M. Levelut, Chem. Commun. 1985, 1794; d) M. Kaller, S. Laschat, Top. Curr. Chem 2012, 318, 109 .

[7] S. Suarez, O. Mamula, R. Scopelliti, B. Donnio, D. Guillon, E. Terazzi, C. Piguet, J.-C. G. Buenzli, New J. Chem. 2005, 29, 1323.

[8] Y. Ma, T. Marzalek, Z. Yuan, R. Stangenberg, W. Pisula, L. Chen, K Müllen, Chem. Asian J. 2015, 10, 139.

[9] S. K. Nayak, M. Amela-Cortes, C. Roiland, S. Cordier, Y. Molard, Chem. Commun. 2015, 51, 3774.

[10] S. K. Nayak, M. Amela-Cortes, M. M. Neidhardt, S. Beardsworth, J. Kirres, M. Mansueto, S. Cordier, S. Laschat, Y. Molard, Chem. Commun. 2016, 52, 3127

[11] F. A. Cotton, Inorg. Chem. 1964, 3, 1217.

[12] a) S. Cordier, F. Grasset, Y. Molard, M. Amela-Cortes, R. Boukherroub, S. Ravaine, M. Mortier, N. Ohashi, N. Saito, H. Haneda, J. Inorg. Organomet. Polym. Mater. 2015, 25, 189; b) S. M. Wood, M. Prevot, M. Amela-Cortes, S. Cordier, S. J. Elston, Y. Molard, S. M. Morris, Adv. Opt Mater. 2015, 3, 1368; c) M. Prevot, M. Amela-Cortes, S. K. Manna, R Lefort, S. Cordier, H. Folliot, L. Dupont, Y. Molard, Adv. Funct. Mater. 2015, 25, 4966

[13] S. Akagi, S. Fujii, N. Kitamura, Dalton Trans. 2018, 47, 1131.

[14] a) A. W. Maverick, H. B. Gray, J. Am. Chem. Soc. 1981, 103, 1298; b) A. W. Maverick, J. S. Najdzionek, D. MacKenzie, D. G. Nocera, H. B. Gray J. Am. Chem. Soc. 1983, 105, 1878.

[15] a) M. Grätzel, Nature Materials 2014, 13, 838; b) Q. A. Akkerman, M. Gandini, F. Di Stasio, P. Rastogi, F. Palazon, G. Bertoni, J. M. Ball, M. Prato, A. Petrozza, L. Manna, Nature Energy 2016, 2, 16194

[16] B. Li, G. Zhang, Z. Wang, Z. Li, R. Chen, C. Qin, Y. Gao, L. Xiao, S. Jia Scientific Reports 2016, 6, 32662.

[17] U. Resch-Genger, M. Grabolle, S. Cavaliere-Jaricot, R. Nitschke, T. Nann, Nature Methods 2008, 5, 763.

[18] F. D. Jong, D. N. Reinhoudt, in Advances in Physical Organic Chemistry Vol. 17 (Eds.: V. Gold, D. Bethell), Academic Press, 1980, pp. 279.

[19] K. Kirakci, S. Cordier, C. Perrin, Z. Anorg. Allg. Chem. 2005, 631, 411.

[20] J. Kirres, K. Schmitt, I. Wurzbach, F. Giesselmann, S. Ludwigs, M. Ringenberg, A. Ruff, A. Baro, S. Laschat, Org. Chem. Front. 2017, 4, 790.

[21] K.-Y. Lee, T.-H. Kim, Y.-W. Shin, J.-E. Kim, Bull. Kor. Chem. Soc. 2004, 25, 529.

[22] M. Robin, N. Dumait, M. Amela-Cortes, C. Roiland, M. Harnois, E. Jacques, H. Folliot, Y. Molard, Chem. Eur. J. 2018, 24, 4825.

[23] M. Kaller, S. J. Beardsworth, P. Staffeld, S. Tussetschlaeger, F. Giesselmann, S. Laschat, Liq. Cryst. 2012, 39, 607.

[24] K. Costuas, A. Garreau, A. Bulou, B. Fontaine, J. Cuny, R. Gautier, M. Mortier, Y. Molard, J.-L. Duvail, E. Faulques, S. Cordier, Phys. Chem. Chem. Phys. 2015, 17, 28574.

[25] a) M. N. Sokolov, M. A. Mihailov, E. V. Peresypkina, K. A. Brylev, N Kitamura, V. P. Fedin, Dalton Trans. 2011, 40, 6375; b) K. Kirakci, P. Kubat, J. Langmaier, T. Polivka, M. Fuciman, K. Fejfarova, K. Lang Dalton Trans. 2013, 42, 7224.

[26] J. A. Jackson, C. Turro, M. D. Newsham, D. G. Nocera, J. Phys. Chem. 1990, 94, 4500

[27] E. Sakuda, K. Tsuge, T. Sasaki, N. Kitamura, J. Phys. Chem. B 2005, 109,22326 